\title{
REPERCUSSÕES DA LEI MARIA DA PENHA NO ENFRENTAMENTO DA VIOLÊNCIA DOMÉSTICA EM PORTO ALEGRE
}

\author{
Elisângela da Silva ALVESa, Dora Lúcia Leidens Corrêa de OLIVEIRA ${ }^{\text {b }}$, Rosana MAFFACCIOLLI
}

\section{RESUMO}

O presente estudo procurou analisar as repercussões da Lei Maria da Penha no enfrentamento da violência doméstica contra mulheres, na cidade de Porto Alegre, a partir da visão dos profissionais que constituem a rede de atendimento a elas. Foram entrevistados sete profissionais que atuam na rede de atendimento a mulheres vítimas de violência. Os dados sugerem que a Lei promoveu mudanças nos campos da prevenção da violência, da assistência a mulheres e da punição aos agressores, com aumento da visibilidade conferida a esse fenômeno e empoderamento feminino. Conclui-se que o fortalecimento das medidas preconizadas pela Lei Maria da Penha ainda depende de investimentos na qualificação dos profissionais, de ações articuladas entre os locais de atendimento e de crescente utilização da atenção básica para a promoção da saúde de mulheres e famílias expostas à violência.

Descritores: Violência doméstica. Identidade de gênero. Legislação.

\section{RESUMEN}

El presente trabajo buscó analizar las repercusiones de la Ley Maria da Penha en el enfrentamiento de la violencia doméstica contra mujeres en la ciudad de Porto Alegre, a partir de la visión de los profesionales que constituyen la red de atendimiento a ellas. Fueron entrevistados siete profesionales que actúan en la red de atendimiento a mujeres víctimas de violencia. Los datos sugieren que la Ley promovió cambios en el campo de la prevención de la violencia, de la asistencia a mujeres y de la punición a los agresores, con el aumento de la visibilidad dada a ese fenómeno y el empoderamiento femenino. Se concluye que el fortalecimiento de las medidas preconizadas por la Ley Maria da Penha aún depende de inversión en la calificación de los profesionales, de acciones articuladas entre los locales de atendimiento y de creciente utilización de la atención básica para la promoción de la salud de mujeres y las familias expuestas a la violencia.

Descriptores: Violencia doméstica. Identidad de género. Legislación.

Título: Repercusiones de la Ley Maria da Penha en el enfrentamiento de la violencia doméstica en Porto Alegre.

\section{ABSTRACT}

The current paper sought to analyze the repercussions of Maria da Penha Law on addressing the issue of domestic violence against women in the city of Porto Alegre based on the view of professionals who constitute the care network for those women. Seven professionals, who work with the care for women who are victims of violence, were interviewed. Data suggests that the Law has promoted changes in the field of violence prevention, assistance to women and punishment for the perpetrators, and it also increased the attention given to this phenomenon and enhanced female empowerment. It is concluded that the strengthening of the measures recommended by Maria da Penha Law still depends on investments in professional qualification, articulated actions between the places which provide assistance and the growing use of primary care services in order to improve the health of women and families exposed to violence.

Descriptors: Domestic violence. Gender identity. Legislation.

Title: Repercussions of Maria da Penha Law on addressing domestic violence in Porto Alegre.

\footnotetext{
a Graduada em Enfermagem pela Universidade Federal do Rio Grande do Sul. Discente do Curso de Especialização em Saúde Pública pela Escola de Saúde Pública, RS, Brasil.

b Doutora em Educação. Professora Adjunta da Escola de Enfermagem da UFRGS, Rio Grande do Sul, Brasil.

c Doutoranda em Enfermagem, pelo Programa de Pós-Graduação em Enfermagem da UFGRS. Professora do Curso de Enfermagem e do Curso de Especialização em Saúde Coletiva do Centro Universitário Metodista Ipa, Porto Alegre, Rio Grande do Sul, Brasil.
} 


\section{INTRODUÇÃO}

A violência contra as mulheres constitui-se em uma das principais formas de violação dos direitos humanos ${ }^{(1,2)}$. Em termos legais, a violência doméstica é definida como ato de violência sofrido por mulheres no ambiente doméstico e familiar, baseada no gênero, e que causa morte, lesão, sofrimento físico, sexual ou psicológico e dano moral ou patrimonial ${ }^{(3)}$.

$\mathrm{O}$ reconhecimento dos direitos das mulheres, como direitos humanos, tem resultado na concretização de reivindicações dirigidas à proteção das mulheres na forma de leis e na instalação de equipamentos específicos como é o caso da criação de Delegacias Especializadas de Atendimento à Mulher (DEAM) ${ }^{(4)}$.

Estima-se que $43 \%$ das mulheres brasileiras já vivenciaram algum tipo de violência doméstica ${ }^{(5)}$, porém não há estatísticas oficiais e sistemáticas que possam ser utilizadas para traçar um panorama preciso dessa situação.

A violência doméstica contra mulheres ganhou notoriedade no Brasil através do caso da Sra. Maria da Penha Maia Fernandes, que, durante 15 anos, percorreu instâncias judiciais na tentativa de processar e punir seu agressor, o qual disparou com revólver em suas costas, deixando-a paraplégica. Esse caso se constituiu em um marco para o Direito brasileiro, pois, a partir dele, o Estado finalmente respondeu às demandas relativas à proteção das mulheres contra a violência doméstica ${ }^{(6)}$.

Experiências, em instituições hospitalares e unidades de saúde, sugerem que as questões referentes à violência contra as mulheres ainda são abordadas de forma superficial e com pouco impacto na resolução e prevenção do problema. Além disso, a falta de habilidade dos profissionais de saúde e de outras áreas em lidar com essa situação ecoa na perpetuação de um desequilíbrio de forças que contribui para que mulheres sejam vulneráveis à violência perpetrada, principalmente, pelos seus parceiros.

Com base nessas reflexões e na magnitude do problema, analisaram-se, neste estudo, as repercussões da Lei Maria da Penha (LMP) no enfrentamento do fenômeno da violência doméstica contra mulheres, a partir da visão dos profissionais que atuam em serviços da rede de atendimento às mesmas. Trata-se de produção oriunda de monografia de conclusão de Curso, apresentada ao Curso de Enfermagem, da Universidade Federal do Rio Grande do Sul em 2009(7).

\section{TRAJETÓRIA METODOLÓGICA}

A pesquisa foi do tipo exploratório-descritivo sendo desenvolvida em serviços e instituições que prestam atendimento a mulheres expostas à violência doméstica, no município de Porto Alegre-RS, nas instâncias social, jurídica e de saúde.

$\mathrm{Na}$ instância social, o campo de estudo foi constituído por dois locais: a Casa de Apoio Viva Maria, pertencente ao Programa Municipal de Albergues e que abriga mulheres vítimas de violência, e a Organização Não Governamental (ONG) Maria Mulher - Organização de Mulheres Negras, que age no combate à violência étnico/racial, doméstica e social. Na instância jurídica, o local do estudo foi a Delegacia Especializada de Atendimento à Mulher-DEAM. Na instância de saúde, optou-se pelo Hospital de Pronto Socorro de Porto Alegre (HPS).

Para seleção dos participantes, estabeleceu-se, como critério de inclusão, ter atuação no atendimento a mulheres em situação de violência doméstica há, no mínimo, quatro anos. Tratou-se de garantir, portanto, que esses profissionais tivessem experiência com tais situações após a promulgação da LMP que se deu no ano de 2006.

Sete sujeitos foram entrevistados: dois da Casa de Apoio Viva Maria, dois da ONG Maria MulherOrganização de Mulheres Negras, dois da Delegacia Especializada de Atendimento a Mulher e um do Hospital Pronto Socorro. Todos eram mulheres, com idades que variaram dos 32 aos 58 anos; quanto à escolaridade, uma havia completado o ensino médio e as demais, o ensino superior.

A coleta de dados foi realizada entre setembro e outubro de 2009 e ocorreu por meio de entrevistas individuais semiestruturadas, sendo as mesmas gravadas e transcritas. Utilizou-se formulário contendo perguntas cujo conteúdo refletia: conhecimentos sobre a Lei Maria da Penha, suas repercussões e efetividade; ações realizadas nos locais de atendimento para o enfrentamento da violência e dificuldades enfrentadas para aplicar as medidas previstas na Lei.

A análise das informações seguiu a proposta da análise de conteúdo, cuja organização ocorre em três pólos cronológicos: primeiro, a pré-análise; segundo, a exploração do material e, por último, o tratamento dos resultados, a inferência e a interpretação ${ }^{(8)}$.

As disposições éticas foram apresentadas anteriormente à coleta de dados em projeto de pesquisa o qual foi submetido à Comissão de Pesquisa 
da Enfermagem da Universidade Federal do Rio Grande do Sul, obtendo aprovação em julho de 2009 (Parecer n ${ }^{\circ}$ 19/09, versão 07/2009) e ao Comitê de Ética em Pesquisa (CEP) da Prefeitura Municipal de Porto Alegre, obtendo aprovação em agosto do mesmo ano (Parecer $\mathrm{N}^{\circ}$ 001.038123.09.6).

\section{RESULTADOS E DISCUSSÃO}

Considerando-se os objetivos da pesquisa e o conteúdo das entrevistas, quatro grandes categorias emergiram do processo analítico, as quais foram assim denominadas: "Mudanças relativas à prevenção de violência doméstica contra mulheres", "Mudanças relativas ao acolhimento e à assistência", "Mudanças relativas à punição ao agressor" e "Elementos que dificultam a aplicação da Lei”.

\section{Mudanças relativas à prevenção de violência doméstica contra mulheres}

Na LMP, prevê-se a integração de vários setores da sociedade, a realização de pesquisas e levantamentos sobre o assunto, além da qualificação de profissionais. A comunicação social é uma das instâncias destacadas na Lei como dispositivo importante na prevenção, sendo indicado o enaltecimento de valores éticos e sociais, de forma a coibir estereótipos que legitimem ou exacerbam a violência doméstica e familiar. Na perspectiva educacional, o foco é a promoção de campanhas educativas de prevenção da violência doméstica contra a mulher que divulguem a Lei e os instrumentos de proteção aos direitos humanos das mulheres ${ }^{(3)}$.

Quanto à comunicação, uma das entrevistadas refere o aumento da visibilidade social do fenômeno da violência doméstica contra a mulher como uma das repercussões da LMP:

[...] deu mais visibilidade à violência doméstica. Tanto que falam às vezes na novela, na notícia no Jornal Nacional, eles estão mencionando bastante a Lei Maria da Penha. Então, isso parece que deu visibilidade, mais importância, mais seriedade para a questão da mulher apanhar. (Participante 4)

Alguns autores ${ }^{(9)}$ argumentam que a visibilidade da violência contra as mulheres e a consciência sobre o problema resultam em aumento da demanda de casos dessa natureza aos serviços de saúde, o que requer conhecimento dos profissionais de saúde, com vistas a uma assistência resolutiva.
No que tange à esfera educacional, destacou-se a seguinte fala:

[...] tanto doutorandos, como mestrandos, os próprios alunos do ensino médio pós LMP começaram também a frequentar a Delegacia da Mulher como objeto de estudo [...]. a principal repercussão da Lei é a divulgação da própria violência doméstica, a divulgação dos órgãos[...] nunca a Delegacia da Mulher foi tão pesquisada, tão procurada como pós Lei Maria da Penha. (Participante 1)

As escolas e universidades representam espaços importantes para o processo de socialização de crianças, jovens e adultos, ao proporcionar a aprendizagem de saberes e de valores éticos e morais. Tais instituições constituem-se em espaços propícios para a abordagem das origens da violência, o que implica destacar a significativa influência da ideologia do patriarcado e da socialização de meninos e meninas na produção de situações de violência doméstica contra mulheres ${ }^{(10)}$. Nesse sentido, parece inegável a relevância do aumento da visibilidade do fenômeno da violência doméstica contra mulheres no meio educacional/acadêmico, uma vez que isto pode resultar em igual aumento de interesse e conhecimento sobre as circunstâncias em que ele ocorre.

Outra questão levantada foi o aumento da autonomia feminina. No trecho a seguir, a entrevistada relata mudanças no comportamento das mulheres, produzidas, segundo ela, a partir da LMP.

[...] essa mulher vem mais empoderada, ela vem conhecendo um pouco, basicamente, os caminhos que vai percorrer, vendo o que é possível e muitas vezes nos cobrando: - Tá, e ele não vai sair de casa? E quando vai ser a audiência? (Participante 3)

Um indicativo desse empoderamento foi o aumento nos registros de ocorrência de violência doméstica contra mulheres, constatado pelos participantes que atuam na Delegacia Especializada de Atendimento à Mulher - DEAM - de Porto Alegre. Esse dado sugere que as mulheres passaram a denunciar mais seus agressores:

[...] mulher classe média alta está denunciando seu agressor e está frequentando a Delegacia da Mulher. Por quê? Graças às ações de prevenção de violências dos órgãos, pós Maria da Penha. A mulher que esperava três, quatro agressões, ela está denunciando na primeira 
perturbação, na primeira ameaça. Na primeira injúria, a mulher já está deixando registrado. (Participante 1)

Os depoimentos são indicativos de que a LMP vem impactando positivamente nas ações de proteção e empoderamento das mulheres, principalmente por conta de uma ampliação do seu acesso aos serviços e na divulgação dos seus direitos.

\section{Mudanças relativas ao acolhimento è̀} assistência

Dentre as diversas mudanças propostas na LMP, duas ganharam destaque nas falas dos entrevistados: "reorganização dos serviços de atendimento a mulheres vítimas de violência” e "maior autonomia no atendimento policial”. Quanto à reorganização dos serviços, enfatizaram-se mudanças no modo de atender as envolvidas na situação de violência e a realização de oficinas, além de um maior envolvimento de equipe multidisciplinar no acompanhamento das mulheres e o desenvolvimento de ações de prevenção à violência. A ONG Maria Mulher - Organização de Mulheres Negras, por exemplo, segundo uma participante que atua na organização, agregou, ao seu rol de atividades, a questão da violência de forma a potencializar os efeitos da Lei, uma iniciativa que sugere o reconhecimento da co-responsabilidade de instâncias não governamentais no enfrentamento do fenômeno da violência doméstica contra mulheres.

\begin{abstract}
A Lei fortaleceu um pouco mais a rede. A gente está seguindo aqui um curso de formação de multiplicadoras em violência doméstica no sentido de trabalhar as questões de gênero. (Participante 5)
\end{abstract}

A reorganização dos serviços permite que as mulheres sejam mais bem acolhidas e passem a confiar e a procurar mais os serviços que compõem a rede de atendimento. Outra conseqüência diz respeito às mudanças nos "modos de atender" e nos programas com vistas a respeitar e cumprir as diretrizes e princípios determinados pela Lei.

Segundo os entrevistados, no âmbito dos atendimentos realizados no Hospital de Pronto Socorro, as mulheres passaram a ser mais reconhecidas como vítimas de violência doméstica e, por conseguinte, seus históricos passaram a constituir casos a serem notificados.

Na medida em que há a notificação dos casos, tem-se um panorama mais fidedigno da ocorrência de situações de violência doméstica e, a partir disso, pode-se delinear um perfil dessas situações, o que permite a composição de estratégias mais eficazes na intervenção/erradicação desse fenômeno. O compromisso de todas as instâncias, que compõem a rede de atendimento, deveria ser o de realizar a notificação, algo que, por muito tempo, e por influência de questões culturais que envolvem relações de gênero, não recebeu a devida atenção. Apesar de ser destacada, na presente pesquisa, a melhoria nas notificações dos casos de violência doméstica contra mulheres após a LMP, sabe-se que, neste campo, ainda persistem problemas de registro e consequente subnotificação ${ }^{(11)}$.

Quanto à segurança da mulher, os participantes mencionaram que, após a LMP, a autoridade policial passou a gozar de maior autonomia nos atendimentos. No período anterior à LMP, garantir a proteção das mulheres era uma das dificuldades enfrentadas pelos policiais, pois o agressor poderia, por exemplo, impedir a mulher de retirar, da casa, seus objetos pessoais, sendo necessária a emissão de um mandato expedido por um juiz permitindo essa ação. Muitas vezes, a mulher era encaminhada a uma Casa Abrigo sem documentos, roupas, material escolar das crianças e sem seus medicamentos (não raro para tratamento de distúrbio de humor e ansiedade $\left.{ }^{(12)}\right)$. É o que relata a fala abaixo:

[Após a Lei.] não precisa o juiz dizer se o delegado pode entrar ou não. A delegada vai lá e a própria delegada tem o direito de entrar e pegar os objetos pessoais, documentos e objetos de higiene. (Participante 1)

Diante de um distanciamento abrupto daquilo que lhe é familiar, a mulher torna-se fragilizada e ter, consigo, ao menos os seus objetos pessoais pode contribuir, como dizem alguns autores, para recolocá-la como figura central nas ações que definem o seu destino ${ }^{(13)}$. Trata-se, assim, de devolver, à mulher e aos filhos, condição para continuar realizando suas atividades cotidianas.

\section{Mudanças relativas à punição ao agressor}

Por meio da LMP, foi alterado o Código de Processo Penal, possibilitando, ao juiz, decretar a prisão preventiva do réu. Outra modificação é em relação à Lei de Execução Penal, a qual permite que o juiz determine o comparecimento obrigatório do agressor a programas de recuperação e re-educação. Relativamente 
à punição do agressor, foram lembrados, pelos entrevistados, dois tipos de repercussões da LMP: "possibilidades de medidas protetivas de urgência" e "proibição de aplicação de penas pecuniárias".

As medidas protetivas de urgência consistem da deliberação de medidas que cerceiam a atuação do agressor e que devem ser aplicadas de imediato. Incluem afastamento do lar, suspensão de visitas aos filhos, prestação de alimentos provisionais, entre outras ações ${ }^{(2)}$. Conforme a entrevistada, que atua na DEAM, os procedimentos a serem desencadeados estão mais ágeis com a Lei:

Medidas protetivas, que é uma coisa de urgência, chegam aqui hoje, a gente já vai direto para o Foro e sai, hoje mesmo, a decisão do juiz, e já é marcada a audiência de reconciliação (Participante 2)

Quanto à proibição de aplicação de penas pecuniárias (tais como pagamentos de cestas básicas), a LMP, em seu Art. 17, ordena que fique proibida a aplicação desse tipo de pena, bem como o pagamento isolado de multas ${ }^{(3)}$. Essa modificação força o judiciário a classificar situações de violência, especialmente agressão física, como crime, o que é lembrado nas entrevistas:

\section{[A Lei trouxe] Agilidade maior em penalizar esse homem. Antes da Lei eram apenas de cesta básica. (Participante 3) \\ [A partir da Lei] Acabam as questões de penalidade por cesta básica, com pagamento com dinheiro, serviços comunitários. (Participante 7)}

Historicamente, a penalização de agressores, em casos de violência contra a mulher, tem sido pouco incisiva em função, muitas vezes, de ser esse fenômeno considerado como pertencente à normalidade dos processos sociais. Considera-se, portanto, que ainda existem obstáculos para que a banalização do fenômeno da violência doméstica contra mulheres seja superada.

\section{Elementos que dificultam a aplicação da Lei}

Os profissionais, atuantes na rede de atendimento a mulheres que vivenciaram a violência doméstica, apontam que há dificuldades na aplicabilidade da Lei. Destacam-se, entre elas, os "elementos estruturais" e os "elementos sociais".
Os elementos estruturais referem-se à ausência de equipe técnica qualificada e multidisciplinar e de espaço físico adequado para atendimento às mulheres, além de difícil acesso a serviços especializados, entre outros.

Entende-se como "elementos sociais" aqueles que têm relação com as condições de vida das mulheres e famílias expostas à violência, como é o caso do poder aquisitivo, de problemas de segurança pública e aqueles gerados pelo consumo de álcool e drogas.

Segundo uma das entrevistadas, a existência de outros profissionais, trabalhando dentro da DEAM, além das policiais plantonistas, poderia resultar em benefícios:

A delegacia, em si, não possui uma psicóloga ou uma assistente social lotada dentro da delegacia para atender estas vítimas. Já se teve esta experiência e ela foi positiva. (Participante 1)

A falta de profissionais e a ausência de uma rede integrada e interdisciplinar, que funcione por tempo integral, são dificuldades encontradas nos serviços, principalmente após as 18 horas ou nos finais de semana. Observa-se, também, a inexistência de um projeto comum que se sustente no diálogo entre saberes e programas de atenção. Ao contrário, lida-se com a existência de lógicas muito diversas, sem interfaces comuns e mútua valorização ${ }^{(14,15)}$. Essa constatação está explicitada na fala a seguir:

[...] essa mulher é muito segmentada, ela acaba buscando várias instituições e cada uma atua de forma isolada. Não é dessa forma, tem que haver toda uma conexão, todas as instituições tem que ter conhecimento daquele caso. (Participante 3)

Uma das ações, em que se poderia investir, é a realização de atividades de qualificação profissional, no sentido de preparar os profissionais para lidarem com as situações de sofrimento que a violência usualmente gera e para aplicarem, nos seus campos de atuação, as diretrizes da LMP. Ao realizar as entrevistas, os participantes do estudo relataram que não tem havido uma capacitação adequada. Os depoimentos sugerem que o desconhecimento, por parte dos profissionais, resulta na não efetivação da lei.

[Sobre a qualificação] Mais foi interno, interesse de cada um, largaram para nós a Lei e a gente foi aplicando. (Participante 2) 
Capacitação não houve pra nós, o que houve foi uma apresentação da nova lei. Para os profissionais, há uma defasagem porque ela [a Lei] caiu de paraquedas, sem estrutura nenhuma e sem conhecimento, sem preparo nenhum desta rede [...]. (Participante 3)

A qualificação dos profissionais é uma ação primordial nas mais variadas instâncias de atendimento à mulher. Contudo, para ser efetiva, deve levar em conta a importância do diálogo e o compartilhamento de experiências dos diferentes atores.

Além dos elementos estruturais, os participantes referiram elementos sociais como entraves no cumprimento da LMP, quais sejam: condições de vida das mulheres e problemas relacionados à segurança pública e ao consumo de álcool e drogas.

Segundo os entrevistados, a situação econômica das mulheres constitui-se em um limite importante para a implementação da Lei. Ações programáticas em nível federal, estadual e municipal preveem auxílio financeiro àquelas que encontram dificuldades para organizar suas vidas:

Acho que o grande ganho para as mulheres, que estão passando por essa situação de violência, é que elas já estão pré-candidatas a um programa. Serve para se reestruturar, pois aquele marido, aquele filho, muitas vezes sai e não deixa nada para ela. (Participante 6)

Nesse caso, é importante entender que a Lei e suas diretrizes não dão conta de problemas que vulnerabilizam determinados segmentos sociais. As desigualdades nas relações de gênero são hegemônicas na etiologia da violência doméstica. Por outro lado, há inúmeros outros fatores que concorrem para uma maior suscetibilidade de determinados grupos sociais. Trata-se, aqui, de analisar a chance de exposição das pessoas a condições deletérias, como resultante de um conjunto de aspectos não apenas individuais, mas também coletivos e contextuais que acarretam maior exposição ao dano ${ }^{(16)}$. Assim, considera-se que a noção de vulnerabilidade precisa ser incorporada, também, como base analítica do problema da violência, principalmente ao lidar com os limites das ações mais objetivadas que são promulgadas em leis.

A dependência química dos parceiros (com destaque para o uso do álcool) também é apontada como um fator que predispõe ao ato violento e/ ou à reincidência dos mesmos.
A reincidência de agressores usuários de álcool e droga, depois do que é ouvido aqui na delegacia, infelizmente é de 40 a 50\%. Aquele agressor, que entra aqui e não tem nenhum problema de saúde, não tem uso do álcool e não tem o uso da droga, é 10\% a sua reincidência. (Participante 1)

Manifestações agressivas podem acontecer de forma intermitente e o comportamento adicto do parceiro estimula o sentimento de responsabilização sobre aquele que é visto como doente. Essa condição, somada à dependência emocional e financeira e ao sofrimento psíquico experimentado na família, torna a situação bastante complexa e pouco promissora, no sentido de um possível empoderamento da mulher ${ }^{(12)}$.

Sem ter acesso a ações intersetoriais e interdisciplinares qualificadas e que sejam pautadas na perspectiva de gênero e, ainda, sem incluir, também, o homem na centralidade das ações preventivas e assistenciais, qualquer ação, que pretenda intervir nesta situação, terá seu objetivo frustrado.

\section{CONSIDERAÇÕES FINAIS}

O estudo permite concluir que a LMP promoveu mudanças no cenário do atendimento a mulheres expostas à violência doméstica, particularmente no campo da prevenção, da assistência e da punição.

Com relação à prevenção, destaca-se a influência da Lei no aumento da visibilidade conferida ao fenômeno da violência doméstica e ao problema da desigualdade de poder de gênero entre homens e mulheres.

Já no campo da assistência, os avanços ocorridos, a partir da Lei, foram com relação à maior autonomia da autoridade policial que passou a atuar de forma mais ágil e efetiva na proteção a essas mulheres.

No que tange as penalidades ao agressor, a criação dos Juizados de Violência Doméstica e Familiar, com competência cível e criminal para processar e julgar todos os casos de violência doméstica contra mulheres, tem sido importante no sentido de promover a responsabilização judicial dos agressores.

Assim, a complexidade das situações de violência contra mulheres atinge diversos campos como o social, a educação, a segurança e a saúde. Requerem-se, portanto, novos olhares e a promoção de ações articuladas entre os locais de atendimento. 
Neste sentido, acredita-se que a LMP precisa ser incorporada em todas as instâncias sociais e por todos os atores como importante dispositivo para este enfrentamento.

Acredita-se, ainda, que assumir um compromisso ético e intransigente com a erradicação da violência doméstica é função de todos os atores envolvidos nas redes de apoio sócio-governamentais.

\section{REFERÊNCIAS}

1 Alves SLB, Diniz NMF. Eu digo não, ela diz sim: a violência conjugal no discurso masculino. Rev Bras Enferm. 2005; 58(4): 387-392.

2 Brito DC, Souza JLC, Costa KS. Subnotificação de delitos e violências contra a mulher na cidade de Belém-Pará, Brasil. In: Anais do $11^{\circ}$ Congresso Luso Afro Brasileiro de Ciências Sociais; 2011 ago 07-10; Salvador, Brasil. Salvador: Universidade Federal da Bahia; 2011. 17 p.

3 Brasil. Lei n. 11.340, de 7 de agosto de 2006: cria mecanismos para coibir a violência doméstica e familiar contra a mulher, nos termos do $\S 8^{\circ}$ do art. 226 da Constituição Federal. Brasília(DF); 2006.

4 Silva SB, Oliveira AC. Violência doméstica como tema de estudo em programas de pós-graduação no estado do Rio de Janeiro. Rev Katálysis. 2008; 11(2): 187-94.

5 Fundação Perseu Abramo. Violência contra a mulher. São Paulo: Fundação Perseu Abramo; 2001.

6 AGENDE. Sobrevivi... o relato do caso Maria da Penha. Brasília: Ações em Gênero Cidadania E Desenvolvimento; 2009.

7 Alves ESA. As repercussões da Lei Maria da Penha no enfrentamento da violência doméstica em Porto Alegre [trabalho de conclusão de curso]. Porto Alegre: Escola de Enfermagem, Universidade Federal do Rio Grande do Sul; 2009.

\section{Endereço da autora / Dirección del autor / Author's address}

Rosana Maffacciolli

Est. João de Oliveira Remião, $n^{\circ}$ 3105, ap. 191, Agronomia

91550-001, Porto Alegre, RS

E-mail:rosanamaffac@yahoo.com.br
8 Bardin L. Análise de Conteúdo. $3^{\mathrm{a}}$ ed. Lisboa: Edições 70; 2004.

9 Vieira LB, Padoin SMM, Landerdahl MC. A percepção de profissionais da saúde de um hospital sobre a violência contra as mulheres. Rev Gaúcha Enferm. 2009; 30(4): 609-16

10 Lopes ZA. Políticas Públicas de Enfrentamento à Violência: estudos de gênero e bases para a ação. In: Curado J, Auad D, organizadores. Gênero e políticas públicas: a construção de uma experiência de formação. Campo Grande: Universidade Católica Dom Bosco; 2008. p. 41-52.

11 Monteiro CFS, Araújo TME, Nunes BMVT, Lustosa, AR, Bezerra CMJ. A violência contra a mulher atendida em unidade de urgência: uma contribuição da enfermagem. Rev Enferm. 2006;10(2): 273-279.

12 Deeke LP, Boing AF, Oliveira WF, Coelho EBS. A Dinâmica da Violência Doméstica: uma análise a partir dos discursos da mulher agredida e de seu parceiro. Saúde Soc. 2009;18(2):248-258.

13 Jong LC, Sadala MLA, Tanaka ACD’A. Desistindo da denúncia ao agressor: relato de mulheres vítimas de violência doméstica. Rev Esc Enferm USP. 2008;42(4):744-51.

14 Kiss LB, Schraiber LB, d'Oliveira AFPL. Possibilidades de uma rede intersetorial de atendimento a mulheres em situação de violência. Interface. 2007;11(23):485-501.

15 Osis MJD, Duarte GA, Fagundes A. Violência entre usuárias de unidades de saúde: prevalência, perspectiva e conduta de gestores e profissionais. Rev Saúde Pública. 2012;46(2):351-8.

16 Ayres JRCM, França Junior I, Calazans GJ, Saletti Filho AC. O conceito de vulnerabilidade e as práticas em saúde: novas perspectivas e desafios. In: Czeresnia D, Freitas C M. Promoção da saúde: conceitos, reflexões e tendências. Rio de Janeiro: Fiocruz; 2003. p. $15-38$.

Recebido em: 02.09.2011

Aprovado em: 15.06.2012 